\title{
Protein Kinase C-Theta (PKC $\theta)$ : A Rheostat in T cell Signaling and Cancer
}

\author{
Pulak Ranjan Nath*
}

Laboratory of Pathology, Center for Cancer Research. National Cancer Institute, National Institutes of Health, 10 Center Drive, Bethesda, MD 20812.

\author{
Corresponding author \\ Pulak Ranjan Nath, Laboratory of Pathology, Center for Cancer \\ Research. National Cancer Institute, National Institutes of Health, \\ 10 Center Drive, Bethesda, MD 20812, Tel:+1 (301) 480 4353, \\ Fax:+1 (301) 480 0611; E-Mail: nath@post.bgu.ac.il or pulak. \\ nath@nih.gov.
}

Submitted: 05 May 2017; Accepted: 09 May 2017; Published: 12 May 2017

\begin{abstract}
Protein kinase C-theta (PKC $\theta$ ) is a key enzyme in T lymphocytes signal transduction pathway that works downstream of the activated $T$ cell receptor (TCR) and the CD28 receptor. This protein translocates to the center of the immunological synapse (IS) as T cells encounter an antigen. Depending on the quality and quantity of extracellular antigenic stimuli, $P K C \theta$ differentially phosphorylates and activates different effector molecules that mediate signal transduction into distinct subcellular compartments and activate the major $T$ cell responsive transcription factors, NF- $\kappa B, N F A T$ and AP-1.

Besides having a major biological role in T cells, PKC $\theta$ is also expressed at high levels in gastrointestinal stromal tumors, although the functional importance is not fully clear. The present manuscript shades light on the current understanding on $P K C \theta$ in $T$ cell signaling and cancer.
\end{abstract}

Keywords: Protein kinase C-theta $(\mathrm{PKC} \theta)$; $\mathrm{T}$ cell signaling; Cancer

\section{Introduction}

PKC $\theta$ is a phospholipid-dependent, but $\mathrm{Ca}^{2+}$-independent serine/ threonine kinase, which resides in the cytosol of resting cells. Cell activation mediates it's translocation to the plasma membrane where it interacts with diacylglycerol (DAG). PKC $\theta$ is involved in the formation of the IS, directional release of effector molecules from cytotoxic $\mathrm{T}$ cells towards their specific target cells [1], and above all it is essential for T cell activation and survival [2] .

PKC, being key enzyme in $\mathrm{T}$ cell differentiation and activation, is inactive in a steady state condition as its catalytic domain is bound to a pseudo-substrate motif. Autophosphorylation at two sites of its $\mathrm{C}$ terminus (turn motif and hydrophobic motif) subsequently activates the kinase. However, self-activation of PKC is still under investigation. In the Jurkat $\mathrm{T}$ cells, the activation loop, turn motif and hydrophobic motif are constitutively phosphorylated. No/low phosphorylation of Thr-219 autophosphorylation site of PKC $\theta$ in resting T cells suggests for its inactivity [3]. PI3K and PLC $\gamma 1$ play critical role in the activation of PKC $\theta$. Once activated, PLC $\gamma 1$ leads to the production of second messenger inositol triphosphate (IP3) and diacylglycerol (DAG). IP3 induces $\mathrm{Ca} 2+$ influx whereas DAG activates PKCs [4] . Intracellular location of PKC $\theta$ signs for the activation status of T cells. In resting T cells, PKC $\theta$ is mostly localized in cytoplasm, whereas upon TCR stimulation, PKC $\theta$ translocates to the membrane [5].

Several biochemical studies have shown that the activation and regulation of kinase activity of PKC $\theta$ upon $\mathrm{T}$ cell activation depends on it's translocation to the membrane, where it is phosphorylated by Lck at Tyr90 [6]. Lee et al. have shown that PDK1 interacts with and phosphorylates PKC $\theta$ at threonine 538 located in activation loop [7]. Phosphorylation of this site is critical for PKC $\theta$ kinase activity, and its ability to activate NF$\kappa \mathrm{B}$. Moreover, $\mathrm{PKC} \theta$ undergoes auto-phosphorylation at threonine 219 in the regulatory domain upon T cell activation. Mutation of this site in PKC $\theta$ prevented the proper recruitment of PKC $\theta$ in the activated $\mathrm{T}$ cells, but does not affect its catalytic activity or DAG binding ability [3]. Activation of PKC $\theta$ is thus carefully regulated by multiple mechanisms during $\mathrm{T}$ cell activation.

PKC $\theta$ interacting proteins in $\mathrm{T}$ cells

PKC $\theta$ interacts with multiple proteins and physiological substrates that eventually shape biological functions of $\mathrm{T}$ cells. Below are the some of the important signaling substrates of $\mathrm{PKC} \theta$ in $\mathrm{T}$ cells:

$14-3-3 \tau$

The first PKC $\theta$-binding protein identified was $14-3-3 \tau$, a member of a large family of conserved regulatory proteins expressed in all eukaryotic cells $[8,9]$. PKC $\theta$ was found to coimmunoprecipitate with 14-3-3 $\tau$ in Jurkat T cell lysates and to interact with immobilized glutathione S-transferase (GST)-14-3-3 $\tau$ in a pull-down assay or with soluble GST-14-3-3 $\tau$ in a Far Western overlay assay [10]. $14-3-3 \tau$ is predominantly cytosolic, and its overexpression in Jurkat cells inhibited phorbol ester-induced cytosol-to-membrane translocation of PKC $\theta$. Overexpression of 14-3-3 $\tau$ also inhibited PKC $\theta$-dependent IL-2 production. It is possible that $14-3-3 \tau$ binds PKC $\theta$ only in its inactive conformation and thereby targets PKC $\theta$ to the cytosol and/or protects it from proteolysis. 
Akt/PKB

$\mathrm{Akt} / \mathrm{PKB}$ was found to activate the NF- $\mathrm{B}$ signaling pathway in $\mathrm{T}$ cells $[11,12]$ by mimicking the CD28 costimulatory signal leading to $\mathrm{NF}-\kappa \mathrm{B}$ activation [13]. In addition, studies showed that $\mathrm{PKC} \theta$ and $\mathrm{Akt} / \mathrm{PKB}$ constitutively associate in intact $\mathrm{T}$ cells and bind directly to each other in vitro [14]. Because both PKC $\theta$ and Akt/ $\mathrm{PKB}$ are recruited to the plasma membrane in activated $\mathrm{T}$ cells, their complex is likely to exist in this compartment.

\section{PICOT}

The human PICOT protein was initially identified by Witte et al. in a study aimed at discovering new PKC $\theta$-binding proteins in activated human $\mathrm{T}$ cells. Utilizing the yeast two-hybrid system, they tested binding of bait consisting of catalytically inactive PKC $\theta$ (PKC - K409R) to protein products of a Jurkat cell cDNA library [15]. Most positive clones obtained were found to possess sequences corresponding to a novel gene, which was cloned (GenBank accession no. AAF28844) and further characterized. PICOT is 335 amino acids long; it consists of an amino-terminal thioredoxin (Trx) homology domain, which is required for interaction with PKC $\theta$.

Initial functional characterization of PICOT revealed that it inhibits PKC $\theta$-induced JNK, but not ERK activation, and down regulates $\mathrm{PKC} \theta$-dependent activation of AP- 1 and NF- $\kappa \mathrm{B}$ in TCR-stimulated Jurkat T cells [15]. Because AP-1 and NF- $\kappa$ B are usually activated by various stress signals, these functional effects of PICOT and the conservation of the Trx system and the PICOT-HD domain throughout evolution suggest that PICOT and its relatives may have evolved as proteins that regulate stress-induced signaling pathways in other cell types and organisms via their interaction with kinases.

\section{Cbl}

$\mathrm{Cbl}$ is a ubiquitously expressed cytoplasmic protein that is abundant in the thymus and cells of the hematopoietic system [16-18] . Analysis of Jurkat $\mathrm{T}$ cells demonstrated that $\mathrm{Cbl}$ associates weakly with 14-3-3 proteins in unstimulated cells, an effect that was greatly enhanced by TCR-ligation and by PKC-activating phorbol esters $[19,20]$. The effect of PMA on tyrosine phosphorylation of $\mathrm{Cbl}$ was reversed upon treatment with a PKC-inhibitor GF109203X. Liu et al. found that PKC $\theta$ physically associate with, and phosphorylate, $\mathrm{Cbl}$ [21]. Additional studies revealed that a $\mathrm{C}$-terminal serine-rich motif in $\mathrm{Cbl}$, which is critical for PMA induced 14-3-3 binding, is the target for phosphorylation by $\mathrm{PKC} \theta$.

Fyn and Lck

Fyn and Lck are essential kinases for the normal development and function of mature effector T cells [22]. Fyn was the most prominent tyrosine-phosphorylated protein associated with $\mathrm{PKC} \theta$ [23]. PKC $\theta$ -Fyn interaction was also observed using the yeast two-hybrid system and reciprocal coimmunoprecipitation from $\mathrm{T}$ cell lysates. When tested in vitro, PKC $\theta$ was found to be a substrate for Fyn. In addition, the presence of Fyn increased PKC $\theta$ catalytic activity. An inhibitor of PKC $\theta$ binding to Fyn, TER14687, abrogated PKC $\theta$ redistribution in CD3-stimulated $\mathrm{T}$ cells and decreased cytokine production in a dose-dependent manner. As noted above, T cell activation is followed by tyrosine phosphorylation of PKC $\theta$ [6]. Phosphorylation was mediated by Lck, which also interacted directly with the PKC $\theta$ regulatory domain as demonstrated by pull-down with GST-fusion proteins, coimmunoprecipitation, and an overlay assay. Lck association with $\mathrm{PKC} \theta$ could be observed in resting cells, increased following $\mathrm{T}$ cell activation, and involved both the SH2 and SH3 domains of Lck. Other important signaling proteins that are found to interact with $\mathrm{PKC} \theta$ in $\mathrm{T}$ cell includes SPAK, CARMA, Moesin and HePTP, which are discussed in great details elsewhere [24].

Localization of PKC $\theta$ in the immunological synapse PKC $\theta$ colocalizes with the TCR in the central supramolecular activation cluster (cSMAC) [25]. T cell surface receptor engagement triggers signaling cascades that result in the recruitment of multiple membrane-anchored and cytoplasmic effector molecules, including kinases, adaptor proteins,and cytoskeletal components, to the IS [26]. PKC $\theta$ attracted significant attention when it was found to be one of the most prominent proteins and the only PCK among all the isoforms selectively translocating to the IS $[25,27]$. PKC $\theta$ is found to be recruited to the junction between the cSMAC and peripheral (p) SMAC and co-localizes with TCRs in a CD28 co-stimulatory-dependent manner [25, 27, 28]. Additional high-resolution imaging analysis by TIRF microscopy demonstrated that PKC $\theta$ colocalizes with $\mathrm{CD} 28$, and demonstrated that the cSMAC is divided into two structurally and functionally distinct compartments: a central TCR- high compartment, where signaling is terminated and TCR-associated signaling complexes are internalized and degraded [29], and an outer TCR-low "ring" where PKC $\theta$ and CD28 colocalize [30]. Further studies have shown that $\mathrm{T}$ cells expressing $\mathrm{PKC} \theta$ periodically break open the pSMAC to create an asymmetric focal zone accumulation pattern that relocates to nearby areas where the pSMAC reformed [31]. This periodic breaking of the symmetric pSMAC to form a polarized focal zone allows short bursts of migration, facilitating $\mathrm{T}$ cell interaction with multiple antigen presenting cells [32]. A recent study has identified a unique region of $\mathrm{PKC} \theta$, called the $\mathrm{V} 3$ domain, that is responsible for the selective translocation of PKC $\theta$ to the IS [33]. The PKC $\theta-$ Lck-CD28 interaction explains why $\mathrm{PKC} \theta$ recruitment to the IS depends on $\mathrm{CD} 28$ co-stimulation. However, in a different study the active kinase domain of PKC $\theta$ was reported to be essential for PKC $\theta$ translocation into the IS [34] and is not clear why there is a discrepancy. One possibility is that the two studies used different sources of T cells: primary $\mathrm{T}$ cells transduced with retrovirus and a D10 cell line. In contrast to conventional T cells, PKC $\theta$ does not translocate to IS of Tregs. In fact it is actually sequestered away from the IS [35], suggesting that the function of PKC $\theta$ in Tregs is likely to be different from its functions in conventional T cells. Altogether, the fact that selective translocation of PKC $\theta$ (but not other isoforms of PKC) to the IS is critical for $\mathrm{T}$ cell activation, strongly suggests it has unique functions in mediating TCR signals, and that selective inhibition of PKC $\theta$ could specifically interfere with $\mathrm{T}$ cell function.

Role of PKC $\theta$ in $T$ cell activation and signaling pathways The major PKC $\theta$-mediated TCR signaling pathways are illustrated in figure 1. Cytoskeletal components play critical roles in signal transduction from the IS through TCR and ensuing events leading to $\mathrm{T}$ cell activation. Intracellular location of $\mathrm{PKC} \theta$ is critical for its function in mediating TCR signals. In resting T cells, PKC $\theta$ is mostly localized in cytoplasm. Upon TCR stimulation, PKC $\theta$ translocates to the membrane detergent insoluble regions called lipid rafts [5]. Vav was found to promote the translocation of PKC $\theta$ from the cytosol to the membrane and cytoskeleton [36]. It also induced $\mathrm{PKC} \theta$ activation in a $\mathrm{CD} 3 / \mathrm{CD} 28$ co stimulation 
pathway that was dependent on Rac and actin cytoskeleton reorganization. In addition, a TCR/CD28-coupled Vav signaling pathway that mediated the activation of JNK and the IL-2 gene, and upregulated CD69 expression, was dependent on intact PKC $\theta$ function because these Vav-induced responses were inhibited by a dominant-negative PKC $\theta$ mutant or by a selective $\mathrm{PKC} \theta$ inhibitor [36]. Also in another study, membrane or lipid raft recruitment of PKC $\theta$ was absent in T cells treated with PI3K inhibitors and was enhanced by constitutively active PI3K. These findings reveal that the Vav/Rac- and PI3K-dependent pathway promotes the recruitment of $\mathrm{PKC} \theta$ to the $\mathrm{T}$ cell synapse and its activation [36, 37]. Activation of $\mathrm{T}$ lymphocytes, in addition, requires sustained physical interaction of the TCR with a major histocompatibility complex (MHC)-presented peptide Ag. Such interaction leads to activation of the Src family protein tyrosine kinase (PTK) Lck [4] and then recruitment of ZAP70 and subsequent recruitment of the adaptor proteins LAT, SLP76, and VAV. LAT then recruits PLC $\gamma 1$ $[38,39]$, which catalyzes IP3 [4]. In addition to DAG, PKC $\theta$ activation also seems to require phosphorylation of threonine 538 (T538) in its activation loop [7, 40]. A recent study indicates that GLK is the upstream kinase responsible for T538 phosphorylation [41]. However, productive $\mathrm{T}$ cell activation depends on an additional signal that can be provided by several costimulatory receptors. The major costimulatory signal for $\mathrm{T}$ cell activation is provided by interaction of the $\mathrm{T}$ cell surface molecule CD28 with its CD80/CD86 (B7-1/B7-2) ligands on APCs [42]. The combination of signals from TCR and CD28 leads to activation of downstream transcription factor, followed by the activation of IL-2 gene promoter. In the absence of a CD28 signal, T cells enter to a stable state of unresponsiveness termed as anergy [43]. The analysis of $\mathrm{PKC}^{-/-} \mathrm{T}$ cells [44] revealed that two transcription factors, i.e., nuclear factor $\kappa \mathrm{B}(\mathrm{NF}-\kappa \mathrm{B})$ and activator protein-1 (AP-1) are targets of $\mathrm{PKC} \theta$ in TCR/CD28- costimulated $\mathrm{T}$ cells. The PKC $\theta$-mediated activation of these two transcription factors requires the integration of signals generated by the TCR and $\mathrm{CD} 28$. Later analysis of $\mathrm{PKC} \theta^{-/-}$mice revealed, however, that $\mathrm{Ca}^{2+}$ signals and, consequently, NFAT activation, are also impaired in $\mathrm{PKC}^{-/-} \mathrm{T}$ cells $[45,46]$. Consistent with the important role of $\mathrm{PKC} \theta$ in IL-2 promoter activation, the mature $\mathrm{T}$ cells of $\mathrm{PKC} \theta^{-/}$ mice display a severe defect in TCR/CD28-induced proliferation and IL-2 secretion, defects that can largely be rescued by the addition of exogenous IL-2 [44, 46].

Transcription factor NF- $\kappa \mathrm{B}$ is activated upon TCR crosslinking, and is critical for $\mathrm{T}$ cell survival and activation [43, 44]. In unstimulated $\mathrm{T}$ cells, NF- $\kappa \mathrm{B}$ is sequestered in the cytoplasm by $\mathrm{I} \kappa \mathrm{B} . \mathrm{T}$ cell activation results in phosphorylation and degradation

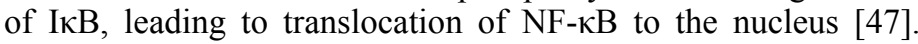
Phosphorylation of I $\mathrm{B}$ is mediated by I $\mathrm{B}$ kinase (IKK) complex, which contains two catalytic subunits, IKK $\alpha$ and IKK $\beta$, and one regulatory subunit, IKK $\gamma$. Previous studies in several $\mathrm{T}$ cell lines had shown that $\mathrm{PKC} \theta$ is essential for activation of $\mathrm{NF}-\kappa \mathrm{B}$ upon TCR-mediated stimulation [45-47]. In agreement with these studies, primary $\mathrm{PKC} \theta^{-/} \mathrm{T}$ cells displayed defects in $\mathrm{NF}-\kappa \mathrm{B}$ activation upon TCR stimulation $[6,48]$. $\mathrm{PKC}^{-/-} \mathrm{T}$ cells failed to activate IKK complex or degrade I $\mathrm{KB}$ [48]. Degradation of $\mathrm{I} \kappa \mathrm{B}$ releases $\mathrm{NF}-\kappa \mathrm{B}$ to the nucleus, where it participates in the activation of target genes essential for $\mathrm{T}$ cell activation [49-51].

Previous in vitro studies using Jurkat cells have implicated JNK in linking PKC $\theta$ to AP1 [52]. However, JNK activation is normal in $\mathrm{PKC}^{-/-} \mathrm{T}$ cells [44], suggesting that an alternative pathway may be involved in PKC $\theta$-regulated AP1 activation. Although the exact mechanism responsible for $\mathrm{PKC} \theta$-mediated activation of AP-1 is still unclear, several studies have provided some insight into this process. Other Ras and MAP kinases like ERK and P38 are involved in PKC $\theta$-mediated AP-1 activation [52, 53]. Li and colleague isolated a PKC $\theta$-interacting upstream MAP kinase, originally termed Ste20/SPS1-related proline and alanine-rich kinase (SPAK), and demonstrated that SPAK selectively interacts with $\mathrm{PKC} \theta$ and participates in $\mathrm{PKC} \theta$-mediated activation of AP-1, but not NF- $\kappa \mathrm{B}[54]$.

Several studies have shown that $\mathrm{PKC} \theta$ enhances the activation of NFAT by stimulating $\mathrm{Ca}^{2+}$ influx; TCR-induced $\mathrm{Ca}^{2+}$ influx, and NFAT activation is defective in T cells from $\mathrm{PKC} \theta^{-/-}$mice $[46,55]$. Although PKC $\theta$ regulates $\mathrm{Ca}^{2+}$ signals via stimulation of PLC $\gamma 1$, it is not known how PKC $\theta$ stimulates PLC $\gamma 1$. The Tek kinase family member Itk may be the missing link. Itk-deficient $\mathrm{T}$ cells display defective $\mathrm{Ca}^{2+}$ influx and PLC $\gamma 1$ activation [56], whereas over expression of Itk leads to stimulation of PLC $\gamma 1$ activity [57]. Therefore, it is possible that $\mathrm{PKC} \theta$ regulates $\mathrm{PLC} \gamma 1$ activation via Itk.

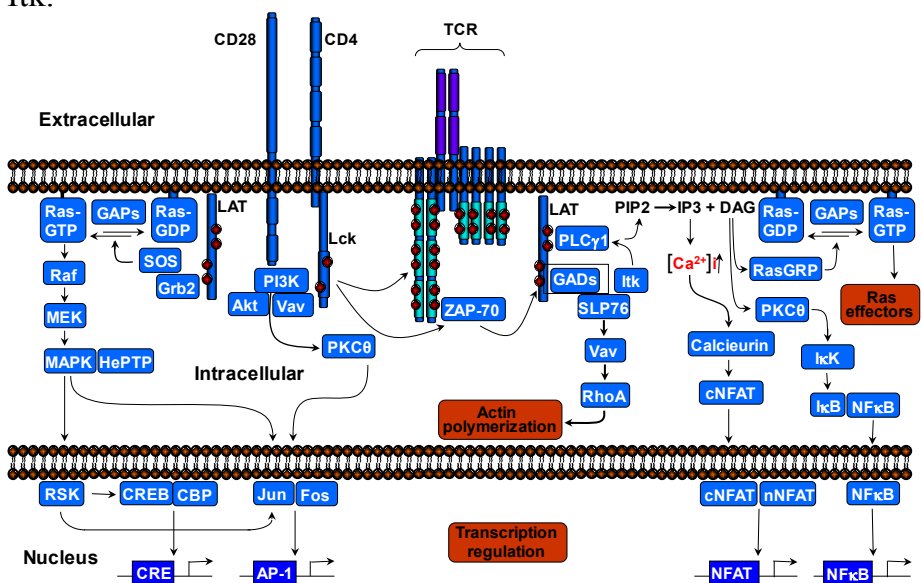

Figure 1: Schematic illustration of PKC $\theta$-regulated signaling pathways in T cell.

Altogether, $\mathrm{PKC} \theta$-mediated TCR signaling regulates multiple signaling pathways including NF- $\kappa \mathrm{B}, \mathrm{AP}-1$, and NFAT that are all critical for $\mathrm{T}$ cell activation. Inhibition of $\mathrm{PKC} \theta$ is therefore expected to prevent $\mathrm{T}$ cell activation by blocking these pathways.

\section{PKC $\theta$ and cancer}

While PKC $\theta$ is not a bona fide oncogene product, it can function as a modulator of signaling pathways in cancer cells and thereby modulate tumor progression and metastasis formation. For example, PKC $\theta$ was found to promote c-Rel-driven mammary tumorigenesis in mice by repressing estrogen receptor $\alpha(\operatorname{ER} \alpha)$ synthesis [58]. In addition, PKC $\theta$ was found to up regulate the expression of Fra-1, which is implicated in oncogenesis, in ERnegative invasive breast cancer cell lines [59].

High expression levels of PKC $\theta$ were observed in a majority of gastrointestinal stromal tumors (GIST) tested [60], and although the role of PKC $\theta$ in GIST cells has not been thoroughly studied, it was suggested to play a role in regulating aberrant c-Kit-dependent signaling pathways that characterize a majority of GIST [60]. 
The availability of the cBioPortal for Cancer Genomics (http:// www.cbioportal.org), which contains data for 17,584 tumor samples from 69 cancer studies, enables analysis potential alterations in the PKC $\theta$ gene, PRKCQ, in different human cancers. A cross-cancer alteration summary revealed a variety of genetic alterations for PRKCQ, predominantly mutations, but also amplifications and deletions in cancer cells from a variety of histological origins $[61,62]$. However, information on the relationship between the genetic changes in PRKCQ and the tumorigenicity and metastatic potential of the individual cancers does not exist.

\section{Key unresolved issues in $\mathrm{PKC} \theta$ function}

Studies indicate relatively normal responsiveness of $\mathrm{PKC}^{-/}$ cells to infectious agents as well as high affinity antigenic stimulation (e.g., OVA) in vivo [63]. However, $\mathrm{PKC} \theta^{-/-} \mathrm{T}$ cell alloreactivity and GVHD- inducing ability is severely impaired, likely due to reduced proliferation and survival in recipient mice [63]. This fundamental difference in the requirement of $\mathrm{PKC} \theta$ in various settings is a key unanswered question, and is central for understanding how detrimental and beneficial functions of T cells in BMT can be separated. The specific inability of $\mathrm{PKC}^{-1-} \mathrm{T}$ cells to induce GVHD can be due to several mutually non-exclusive reasons. First, the conditioning regimen used for BMT may play an important role. Thus, lethal irradiation prior to BMT severely depletes recipient APC required for donor T cell activation. It is possible that reduction in APC impacts $\mathrm{PKC}^{-/-} \mathrm{T}$ cell responses more severely than WT T cells. Interestingly, allograft survival in heart transplantation models showed a relatively small requirement for PKC $\theta$ in transplant rejection $[64,65]$, likely due to presence of compensatory functions of $\mathrm{PKC} \alpha[65]$. Therefore, it is possible that impaired alloreactivity in the absence of $\mathrm{PKC} \theta$ is more pronounced in the BMT setting. Second, it is possible that defects in CD4 and CD8 T cell migration [66] contribute to lack of GVHD induction in the absence of PKC $\theta$. Thus, impaired migration of $\mathrm{PKC}^{-/-} \mathrm{T}$ cells to GVHD target organs such as the gut, lungs, and skin may be responsible for reduced GVHD. Third, the function of PKC $\theta$ in alloreactivity may not be limited to effector $\mathrm{T}$ cell responses. Previous studies investigating a role for PKC $\theta$ in Tregs suggest that $\mathrm{PKC} \theta$ function in Treg may also be important in alloreactivity [35]. While PKC $\theta$ localizes to the immune synapse (IS) in effector $\mathrm{T}$ cell, $\mathrm{PKC} \theta$ is sequestered in a distal complex away from the IS in Treg [35]. As such, PKC $\theta$ is responsible for mediating a negative effect on the suppressive function of Treg. Consequently, PKC $\theta$ inhibition enhances Treg function leading to protection from inflammatory colitis in mice [35]. While PKC $\theta$ inhibition leads to enhance Treg function, $\mathrm{PKC} \theta$ absence does not have the same effect [67]. The underlying reason for this is not completely clear [68]. The easiest albeit simplistic way to understand why PKC $\theta$ absence does not impact anti-infection and anti-tumor responses is to consider a role for functionally redundant pathways. As mentioned above, PKC $\theta$ is involved in regulating activation of NF- $\kappa \mathrm{B}, \mathrm{AP}-$ 1 , and NF-AT. Studies by Marsland and colleagues have shown that microbial stimulation through pattern recognition receptors (PRR) can induce NF- $\kappa \mathrm{B}$ activation in $\mathrm{PKC} \theta^{--} \mathrm{T}$ cells [69-71]. Thus, PRR may play a key functionally redundant role with PKC $\theta$ during infection with microbial agents. In contrast, why anti-tumor responses are only slightly reduced in the absence of $\mathrm{PKC} \theta$ is more difficult to understand. BMT is primarily used for leukemia treatment. Leukemic cells and B lymphocytes have naturally high expression of $\mathrm{MHC}$ and co-stimulatory molecules, reflecting the natural function of these lineages in antigen presentation. In the above-mentioned study [63], A20 B cell lymphoma cells were used as tumor targets. Whether $\mathrm{PKC}^{-/-} \mathrm{T}$ cells are specifically (or only) able to eradicate leukemic tumors can be directly tested by determining PKC $\theta$ requirement in eradication of non-leukemic tumors. Mechanistically, one possibility is that functionally redundant pathways are strongly activated in $\mathrm{PKC} \theta^{-/-} \mathrm{T}$ cells by $\mathrm{A} 20$ and potentially other leukemic tumors. Furthermore, leukemic tumors may represent better targets for $\mathrm{PKC} \theta^{-/-} \mathrm{T}$ cells than epithelial cells targeted during GVHD. Regardless of precise mechanisms, it is likely that both responses to infectious agents and leukemic tumors are maintained in the absence of PKC $\theta$ through functionally redundant pathways. A recent study identified a novel role for $\mathrm{PKC} \theta$ as a transcriptional co-activator capable of interacting with promoters of several immune function genes [72]. How this function impacts alloreactivity and other known functions for $\mathrm{PKC} \theta$ remains to be determined.

\section{Conclusions and future perspectives}

Identification and characterization of the molecular mechanism by which PKC $\theta$ associates with $\mathrm{CD} 28$ and colocalizes with it at the cSMAC has provided important information relevant to the mechanism by which $\mathrm{CD} 28$ and $\mathrm{PKC} \theta$ contribute to signal transduction inTCR/CD28-engaged T cells. These findings also raise new questions relevant to the mechanism of interaction of CD28 and PKC $\theta$ and their specific role in the induction of distinct $\mathrm{T}$ cell-mediated immune responses. One obvious question relates to the mechanism by which PKC $\theta$ is sequestered away from the IS of activated Treg cells. It would be interesting to determine whether a CD28-Lck-PKC $\theta$ tri-partite complex [33] occurs in Treg cells, and determine the mechanism that enables $\mathrm{PKC} \theta$ recruitment away from the Treg-APC contact area. A plausible explanation for this process is that CTLA-4 competes with CD28 in recruitment to the cSMAC [73]. In addition, it is not known whether PKC $\theta$ is involved in a second signal delivery during the costimulation of $\gamma \delta$ T cells [74].

Despite the extensive amount of studies on the biology of PKC $\theta$ in mouse $\mathrm{T}$ cells, very little is known about its regulation and function in human $\mathrm{T}$ cells. This is a substantial gap that would need to be filled if PKC $\theta$ is destined to fulfill its promise as a clinically relevant drug target [75]. As discussed earlier, the dependence of $\mathrm{T}$ cell-mediated deleterious autoimmune/inflammatory responses, including GvHD, on PKC $\theta$ make it an attractive clinical drug target with potentially advantage over global toxic immunosuppressive drugs such as calcineurin inhibitors (e.g., cyclosporineA). Indeed, there has been considerable interest among pharmaceutical companies in developing small molecules elective PKC $\theta$ catalytic activity inhibitors [76]. Nevertheless, small molecule inhibitors of protein kinases often have toxic side effects because of their lack of absolute specificity, which reflects the relatively high conservation of catalytic domains within the protein kinase family, and even more so within the PKC family. Furthermore, since catalytic kinase inhibitors in current clinical use are ATP competitors, they need to be used at relatively high and potentially toxic concentrations to effectively compete with ATP. Thus, there has recently been considerable interest and progress in developing allosteric kinase inhibitors, which bind to sites other than the catalytic site in kinases and, thus, are likely to be much more selective and less toxic [77]. A study demonstrates a new potential approach for attenuating PKC $\theta$-dependent functions utilizing allosteric compounds based on the critical PR motif in the V3 domain of PKC $\theta$ that will block 
its Lck- mediated association with CD28 and recruitment to the IS [33], which is obligatory for its downstream signaling functions. This new approach could serve as a basis for the development of new therapeutic agents that would selectively suppress undesired $\mathrm{T}$ cell-mediated inflammation and autoimmunity or prevent graft rejection, while preserving desired immunity, such as anti viral and anti tumor responses.

\section{Acknowledgment}

The author is thankful to the Planning and Budgeting Committee (PBC), Council for Higher Education, Israel for offering the 'PBC Outstanding Postdoctoral Fellowship'. The Author is grateful to Dr. Noah Isakov and Dr. Alex Braiman for their support and suggestions during the study.

\section{Conflict of Interest}

The author declares no conflict of interest.

\section{References}

1. Huse M (2012) Microtubule-organizing center polarity and the immunological synapse: protein kinase $\mathrm{C}$ and beyond. Front.Immunol 3: 235.

2. Zhang EY, Kong KF, Altman A (2013) The Yin and Yang of protein kinase C-theta (PKCtheta): a novel drug target for selective immunosuppression. Adv.Pharmacol 66: 267-312.

3. Thuille N, Heit I, Fresser F, Krumbock N, Bauer B, et al. (2005) Critical role of novel Thr-219 autophosphorylation for the cellular function of PKCtheta in T lymphocytes. EMBO J 24: 3869-3880.

4. Weiss A, Littman DR (1994) Signal transduction by lymphocyte antigen receptors. Cell 76: 263-274.

5. Bi K, Altman A (2001) Membrane lipid microdomains and the role of PKCtheta in T cell activation. Semin.Immunol 13: 139-146.

6. Liu Y, Witte S, Liu YC, Doyle M, Elly C, et al. (2000) Regulation of protein kinase Ctheta function during $\mathrm{T}$ cell activation by Lck-mediated tyrosine phosphorylation. J.Biol. Chem 275: 3603-3609.

7. Lee KY, D’Acquisto F, Hayden MS, Shim JH, Ghosh S (2005) PDK1 nucleates $\mathrm{T}$ cell receptor-induced signaling complex for NF-kappaB activation. Science 308: 114-118.

8. Fu H, Subramanian RR, Masters SC (2000) 14-3-3 Proteins: Structure, Function, and Regulation. Annu.Rev.Pharmacol. Toxicol 40: 617-647.

9. Baldin V (2000) 14-3-3 Proteins and Growth Control. Prog. Cell Cycle Res 4: 49-60.

10. Meller N, Liu YC, Collins TL, Bonnefoy-Berard N, Baier G, et al. (1996) Direct interaction between protein kinase $C$ theta (PKC theta) and 14-3-3 tau in T cells: 14-3-3 overexpression results in inhibition of $\mathrm{PKC}$ theta translocation and function. Mol.Cell.Biol 16: 5782-5791.

11. Kane LP, Shapiro VS, Stokoe D, Weiss A (1999) Induction of NF-kappaB by the Akt/PKB kinase. Curr.Biol 9: 601-604.

12. Jones RG, Parsons M, Bonnard M, Chan VS, Yeh WC, et al. (2000) Protein kinase B regulates T lymphocyte survival, nuclear factor kappaB activation, and $\mathrm{Bcl}-\mathrm{X}(\mathrm{L})$ levels in vivo. J.Exp.Med 191: 1721-1734.

13. Kane LP, Andres PG, Howland KC, Abbas AK, Weiss A (2001) Akt provides the CD28 costimulatory signal for upregulation of IL-2 and IFN-gamma but not TH2 cytokines. Nat.Immunol 2: 37-44.
14. Bauer B, Krumbock N, Fresser F, Hochholdinger F, Spitaler $\mathrm{M}$, et al. (2001) Complex formation and cooperation of protein kinase $\mathrm{C}$ theta and Akt1/protein kinase B alpha in the NF-kappa B transactivation cascade in Jurkat T cells. J.Biol. Chem 276: 31627-31634

15. Witte S, Villalba M, Bi K, Liu Y, Isakov N, et al. (2000) Inhibition of the c-Jun N-terminal kinase/AP-1 and NFkappaB pathways by PICOT, a novel protein kinase $\mathrm{C}$-interacting protein with a thioredoxin homology domain. J.Biol.Chem 275: 1902-1909.

16. Smit L, Borst J (1997) The Cbl family of signal transduction molecules. Crit.Rev.Oncog 8: 359-379.

17. Liu YC, Altman A (1998) Cbl: complex formation and functional implications. Cell.Signal 10: 377-385.

18. Thien CB, Langdon WY (1998) c-Cbl: a regulator of T cell receptor-mediated signalling. Immunol.Cell Biol 76: 473-482.

19. Liu YC, Elly C, Yoshida H, Bonnefoy-Berard N, Altman A (1996) Activation-modulated association of 14-3-3 proteins with Cbl in T cells. J.Biol.Chem 271: 14591-14595.

20. Liu YC, Liu Y, Elly C, Yoshida H, Lipkowitz S, et al. (1997) Serine phosphorylation of $\mathrm{Cbl}$ induced by phorbol ester enhances its association with 14-3-3 proteins in T cells via a novel serine-rich 14-3-3-binding motif. J.Biol.Chem 272: 9979-9985.

21. Liu Y, Liu YC, Meller N, Giampa L, Elly C, et al. (1999) Protein kinase $\mathrm{C}$ activation inhibits tyrosine phosphorylation of $\mathrm{Cbl}$ and its recruitment of Src homology 2 domaincontaining proteins. J.Immunol 162: 7095-7101.

22. Perlmutter RM, Levin SD, Appleby MW, Anderson SJ, Alberola-Ila J (1993) Regulation of lymphocyte function by protein phosphorylation. Annu.Rev.Immunol 11: 451-499.

23. Ron D, Napolitano EW, Voronova A, Vasquez NJ, Roberts $\mathrm{DN}$, et al. (1999) Direct interaction in T-cells between thetaPKC and the tyrosine kinase p59fyn. J.Biol.Chem 274: 19003-19010.

24. Isakov $\mathrm{N}$, Altman A (2002) Protein kinase $\mathrm{C}$ (theta) in T cell activation. Annu.Rev.Immunol 20: 761-794.

25. Monks CR, Freiberg BA, Kupfer H, Sciaky N, Kupfer A (1998) Three-dimensional segregation of supramolecular activation clusters in T cells. Nature 395: 82-86.

26. Dustin ML, Chakraborty AK, Shaw AS (2010) Understanding the structure and function of the immunological synapse. Cold Spring Harb Perspect.Biol 2: a002311.

27. Monks CR, Kupfer H, Tamir I, Barlow A, Kupfer A (1997) Selective modulation of protein kinase $\mathrm{C}$-theta during T-cell activation. Nature 385: 83-86.

28. Somersalo K, Anikeeva N, Sims TN, Thomas VK, Strong RK, et al. (2004) Cytotoxic T lymphocytes form an antigenindependent ring junction. J.Clin.Invest 113: 49-57.

29. Vardhana S, Choudhuri K, Varma R, Dustin ML (2010) Essential role of ubiquitin and TSG101 protein in formation and function of the central supramolecular activation cluster. Immunity 32: 531-540.

30. Yokosuka T, Kobayashi W, Sakata-Sogawa K, Takamatsu M, Hashimoto-Tane A, et al. (2008) Spatiotemporal regulation of $\mathrm{T}$ cell costimulation by TCR-CD28 microclusters and protein kinase $C$ theta translocation. Immunity 29: 589-601.

31. Sims TN, Soos TJ, Xenias HS, Dubin-Thaler B, Hofman JM, et al. (2007) Opposing effects of PKCtheta and WASp on symmetry breaking and relocation of the immunological synapse. Cell 129: 773-785. 
32. Lindquist RL, Shakhar G, Dudziak D, Wardemann H, Eisenreich T, et al. (2004) Visualizing dendritic cell networks in vivo. Nat.Immunol 5: 1243-1250.

33. Kong KF, Yokosuka T, Canonigo-Balancio AJ, Isakov N, Saito T, et al. (2011) A motif in the V3 domain of the kinase PKC-theta determines its localization in the immunological synapse and functions in T cells via association with CD28. Nat.Immunol 12: 1105-1112.

34. Cartwright NG, Kashyap AK, Schaefer BC (2011) An active kinase domain is required for retention of PKCtheta at the $\mathrm{T}$ cell immunological synapse. Mol.Biol.Cell 22: 3491-3497.

35. Zanin-Zhorov A, Ding Y, Kumari S, Attur M, Hippen KL, et al. (2010) Protein kinase C-theta mediates negative feedback on regulatory T cell function. Science 328: 372-376.

36. Villalba M, Coudronniere N, Deckert M, Teixeiro E, Mas $\mathrm{P}$, et al. (2000) A novel functional interaction between Vav and PKCtheta is required for TCR-induced T cell activation. Immunity 12: 151-160.

37. Villalba M, Bi K, Hu J, Altman Y, Bushway P, et al. (2002) Translocation of PKC[theta] in $\mathrm{T}$ cells is mediated by a nonconventional, PI3-K- and Vav-dependent pathway, but does not absolutely require phospholipase C. J.Cell Biol 157: 253-263.

38. Clements JL (2003) Known and potential functions for the SLP-76 adapter protein in regulating T-cell activation and development. Immunol.Rev 191: 211-219.

39. Berg LJ, Finkelstein LD, Lucas JA, Schwartzberg PL (2005) Tec family kinases in T lymphocyte development and function. Annu.Rev.Immunol 23: 549-600.

40. Liu Y, Graham C, Li A, Fisher RJ, Shaw S (2002) Phosphorylation of the protein kinase C-theta activation loop and hydrophobic motif regulates its kinase activity, but only activation loop phosphorylation is critical to in vivo nuclearfactor-kappaB induction. Biochem.J 361: 255-265.

41. Chuang HC, Lan JL, Chen DY, Yang CY, Chen YM, et al. (2011) The kinase GLK controls autoimmunity and NFkappaB signaling by activating the kinase PKC-theta in $\mathrm{T}$ cells. Nat.Immunol 12: 1113-1118.

42. Chambers CA, Allison JP (1999) Costimulatory regulation of T cell function. Curr.Opin.Cell Biol 11: 203-210.

43. Schwartz RH (1997) T cell clonal anergy. Curr.Opin.Immunol 9: 351-357.

44. Sun Z, Arendt CW, Ellmeier W, Schaeffer EM, Sunshine MJ, et al. (2000) PKC-theta is required for TCR-induced NFkappaB activation in mature but not immature $\mathrm{T}$ lymphocytes. Nature 404: 402-407.

45. Manicassamy S, Sadim M, Ye RD, Sun Z (2006) Differential roles of PKC-theta in the regulation of intracellular calcium concentration in primary T cells. J.Mol.Biol 355: 347-359.

46. Pfeifhofer C, Kofler K, Gruber T, Tabrizi NG, Lutz C, et al. (2003) Protein kinase $\mathrm{C}$ theta affects $\mathrm{Ca}^{2+}$ mobilization and NFAT cell activation in primary mouse T cells. J.Exp.Med 197: 1525-1535.

47. McGuire KL, Iacobelli M (1997) Involvement of Rel, Fos, and Jun proteins in binding activity to the IL-2 promoter CD28 response element/AP-1 sequence in human $\mathrm{T}$ cells. J.Immunol 159: 1319-1327.

48. Spitaler M, Cantrell DA (2004) Protein kinase C and beyond. Nat.Immunol 5: 785-790.

49. Weil R, Schwamborn K, Alcover A, Bessia C, Di Bartolo, et al. (2003) Induction of the NF-kappaB cascade by recruitment of the scaffold molecule NEMO to the T cell receptor. Immunity 18: $13-26$.

50. Lin X, Wang D (2004) The roles of CARMA1, Bcl10, and MALT1 in antigen receptor signaling. Semin.Immunol 16: 429-435.

51. Weil R, Israel A (2004) T-cell-receptor- and B-cell-receptormediated activation of NF-kappaB in lymphocytes. Curr. Opin.Immunol 16: 374-381.

52. Baier-Bitterlich G, Uberall F, Bauer B, Fresser F, Wachter $\mathrm{H}$, et al. (1996) Protein kinase C-theta isoenzyme selective stimulation of the transcription factor complex AP-1 in T lymphocytes. Mol.Cell.Biol 16: 1842-1850.

53. Shaulian E, Karin M (2002) AP-1 as a regulator of cell life and death. Nat.Cell Biol 4: E131-136.

54. Li Y, Hu J, Vita R, Sun B, Tabata H, et al. (2004) SPAK kinase is a substrate and target of PKCtheta in T-cell receptor-induced AP-1 activation pathway. EMBO J 23: 1112-1122.

55. Manicassamy S, Gupta S, Huang Z, Sun Z (2006) Protein kinase $C$-theta-mediated signals enhance CD4+ T cell survival by up-regulating Bcl-xL. J.Immunol 176: 6709-6716.

56. Liu KQ, Bunnell SC, Gurniak CB, Berg LJ (1998) T cell receptor-initiated calcium release is uncoupled from capacitative calcium entry in Itk-deficient T cells. J.Exp.Med 187: 1721-1727.

57. Tomlinson MG, Kane LP, Su J, Kadlecek TA, Mollenauer MN, et al. (2004) Expression and function of Tec, Itk, and Btk in lymphocytes: evidence for a unique role for Tec. Mol.Cell. Biol 24: 2455-2466.

58. Belguise K, Sonenshein GE (2007) PKCtheta promotes c-Rel-driven mammary tumorigenesis in mice and humans by repressing estrogen receptor alpha synthesis. J.Clin.Invest 117: 4009-4021.

59. Belguise K, Milord S, Galtier F, Moquet-Torcy G, Piechaczyk M, et al. (2012) The PKCtheta pathway participates in the aberrant accumulation of Fra-1 protein in invasive ERnegative breast cancer cells. Oncogene 31: 4889-4897.

60. Kim KM, Kang DW, Moon WS, Park JB, Park CK, et al. (2006) PKCtheta expression in gastrointestinal stromal tumor. Mod.Pathol 19: 1480-1486.

61. Cerami E, Gao J, Dogrusoz U, Gross BE, Sumer SO, et al. (2012) The cBio cancer genomics portal: an open platform for exploring multidimensional cancer genomics data. Cancer. Discov 2: 401-404.

62. Gao J, Aksoy BA, Dogrusoz U, Dresdner G, Gross B, et al. (2013) Integrative analysis of complex cancer genomics and clinical profiles using the cBioPortal. Sci.Signal 6: pl1.

63. Valenzuela JO, Iclozan C, Hossain MS, Prlic M, Hopewell E, et al. (2009) PKCtheta is required for alloreactivity and GVHD but not for immune responses toward leukemia and infection in mice. J.Clin.Invest 119: 3774-3786.

64. Manicassamy S, Yin D, Zhang Z, Molinero LL, Alegre ML, et al. (2008) A critical role for protein kinase C-theta-mediated $\mathrm{T}$ cell survival in cardiac allograft rejection. J.Immunol 181: 513-520.

65. Gruber T, Hermann-Kleiter N, Pfeifhofer-Obermair C, LutzNicoladoni C, Thuille N, et al. (2009) PKC theta cooperates with PKC alpha in alloimmune responses of $\mathrm{T}$ cells in vivo. Mol.Immunol: 46: 2071-2079.

66. Letschka T, Kollmann V, Pfeifhofer-Obermair C, LutzNicoladoni C, Obermair GJ, et al. (2008) PKC-theta selectively controls the adhesion-stimulating molecule Rap1. 
Blood 112: 4617-4627.

67. Gupta S, Manicassamy S, Vasu C, Kumar A, Shang W, et al. (2008) Differential requirement of PKC-theta in the development and function of natural regulatory T cells. Mol. Immunol 46: 213-224.

68. Zanin-Zhorov A, Dustin ML, Blazar BR (2011) PKCtheta function at the immunological synapse: prospects for therapeutic targeting. Trends Immunol 32: 358-363.

69. Marsland BJ, Nembrini C, Schmitz N, Abel B, Krautwald S, et al. (2005) Innate signals compensate for the absence of PKC\{theta\} during in vivo CD8(+) T cell effector and memory responses. Proc.Natl.Acad.Sci.U.S.A. 102: 14374-14379.

70. Marsland BJ, Nembrini C, Grun K, Reissmann R, Kurrer M, et al. (2007) TLR ligands act directly upon T cells to restore proliferation in the absence of protein kinase $\mathrm{C}$-theta signaling and promote autoimmune myocarditis. J.Immunol 178: 34663473.

71. Marsland BJ, Kopf M (2008) T-cell fate and function: PKCtheta and beyond. Trends Immunol 29: 179-185.

72. Sutcliffe EL, Bunting KL, He YQ, Li J, Phetsouphanh C, et al. (2011) Chromatin-associated protein kinase C-theta regulates an inducible gene expression program and micro RNAs in human T lymphocytes. Mol.Cell 41: 704-719.

73. Yokosuka T, Kobayashi W, Takamatsu M, Sakata-Sogawa K, Zeng H, et al. (2010) Spatiotemporal basis of CTLA-4 costimulatory molecule-mediated negative regulation of $\mathrm{T}$ cell activation. Immunity 33: 326-339.

74. Ribot JC, debarros A, Silva-Santos B (2011) Searching for "signal 2": costimulation requirements of gammadelta $\mathrm{T}$ cells. Cell Mol.Life Sci 68: 2345-2355.

75. Altman A, Kong KF (2012) PKCtheta: a new target for selective immunosuppression. Expert Rev.Clin.Immunol 8: 205-208.

76. Evenou JP, Wagner J, Zenke G, Brinkmann V, Wagner K, et al. (2009) The potent protein kinase C-selective inhibitor AEB071 (sotrastaurin) represents a new class of immunosuppressive agents affecting early T-cell activation. J.Pharmacol.Exp.Ther 330: 792-801.

77. Lamba V, Ghosh I (2012) New directions in targeting protein kinases: focusing upon true allosteric and bivalent inhibitors. Curr.Pharm.Des 18: 2936-2945.
Copyright: (02017 Pulak Ranjan Nath. This is an open-access article distributed under the terms of the Creative Commons Attribution License, which permits unrestricted use, distribution, and reproduction in any medium, provided the original author and source are credited. 